NBER WORKING PAPER SERIES

\title{
AGGREGATE CONSEQUENCES OF \\ LIMITED CONTRACT ENFORCEABILITY
}

\author{
Thomas Cooley \\ Ramon Marimon \\ Vincenzo Quadrini \\ Working Paper 10132 \\ http://www.nber.org/papers/w10132
NATIONAL BUREAU OF ECONOMIC RESEARCH
1050 Massachusetts Avenue
Cambridge, MA 02138 \\ December 2003
}

The views expressed herein are those of the authors and not necessarily those of the National Bureau of Economic Research.

(C2003 by Thomas Cooley, Ramon Marimon, and Vincenzo Quadrini. All rights reserved. Short sections of text, not to exceed two paragraphs, may be quoted without explicit permission provided that full credit, including (C) notice, is given to the source. 
Aggregate Consequences of Limited Contract Enforceability

Thomas Cooley, Ramon Marimon, and Vincenzo Quadrini

NBER Working Paper No. 10132

December 2003

JEL No. E3, G0

\section{$\underline{\text { ABSTRACT }}$}

We study a general equilibrium model in which entrepreneurs finance investment with optimal financial contracts. Because of enforceability problems, contracts are constrained efficient. We show that limited enforceability amplifies the impact of technological innovations on aggregate output. More generally, we show that lower enforceability of contracts will be associated with greater aggregate volatility. A key assumption for this result is that defaulting entrepreneurs are not excluded from the market.

Thomas Cooley

Department of Economics

Stern School of Business

New York University

44 West Fourth Street

New York, NY 10012

and NBER

tcooley@stern.nyu.edu

Ramon Marimon

Universitat Pompeu Fabra

Ramon Trias Fargas, 25-27

08005 Barcelona, Spain

and NBER

ramon.marimon@upf.edu

Vincenzo Quadrini

Department of Finance and Business Economics

Marshall School of Business

University of Southern California

701 Exposition Blvd.

Los Angeles, CA 90089

and NBER

vquadrin@stern.nyu.edu 


\section{Introduction}

The ability to attract external financing is crucial for the creation of new firms and the expansion of existing ones. For that reason the nature of the financial arrangements between investors and entrepreneurs has important consequences for the growth of firms. One important issue in financial contracting is enforceability, that is, the ability of each side to repudiate the contract. This is especially important because projects often involve specific entrepreneurial expertise and might be worth less to investors without the services of managers who initiated them. At the same time the development of such projects may provide managers with experience that is extremely valuable for starting new projects.

Contractual arrangements that are motivated by limited enforceability are most likely to be important for firms that are small, young and invest in assets that cannot be used as collateral. Albuquerque and Hopenhayn (1997) have shown that these considerations can help to explain some of the growth characteristics of small and young firms. We know for example that smaller and younger firms are less likely to distribute dividends and that, conditional on the initial size, they tend to grow faster and experience greater variability of growth.

Even though financial constraints are important for explaining the growth characteristics of firms, it is not obvious whether they also have important aggregate consequences. The main goal of this paper is to show that financial constraints that arise because of limited contract enforceability can have important aggregate consequences. On the one hand it impairs the efficient allocation of resources with significant welfare consequences. On the other, it increases the sensitivity of the macro economy to the arrival of new technologies that create better investment opportunities.

We study a general equilibrium model where entrepreneurs and investors enter into a long-term contractual relationship which is optimal, subject to enforceability constraints. ${ }^{1}$ Our model is closely related to the partial equilibrium model of Marcet and Marimon (1992) with two important differences. First, we conduct the analysis in a general equilibrium framework. Second, we do not assume that repudiation leads to market exclusion. Once the

\footnotetext{
${ }^{1}$ This paper relates to the literature on optimal lending contracts with the possibility of repudiation such as Alvarez and Jermann (2000), Atkeson (1991), Kehoe and Levine (1993) and Marcet and Marimon (1992). Contributions that explicitly focus on the financing of the firm are Albuquerque and Hopenhayn (1997), Monge (2001) and Quintin (2000).
} 
contract has been signed, the entrepreneur has the ability to start a new investment project by entering into a new contractual relationship. Therefore, the value of repudiation is endogenous in our model and it depends on all the general equilibrium conditions. This is an important difference respect to other macro models with endogenous market incompleteness where agents revert to autarky in case of default. A notable exception is Phelan (1995), although his analysis is limited to steady states.

Within this framework we show that limited enforceability creates a large amplification mechanism for the macroeconomic impact of new technological innovations. More specifically, our theory predicts that economies in which contracts are less enforceable (either because there is no market exclusion or the cost of repudiation is higher) display greater volatility of output than economies with stronger enforceability of contracts.

The mechanism that generates the amplification result can be explained as follows. In each period there are two types of firms: those that are resource constrained (the enforcement constraint is binding) and those that are unconstrained (the enforcement constraint is not binding). The investment behavior of the first group of firms is what generates the amplification result. When a more productive technology arrives, the value of a new investment project increases. Because defaulting entrepreneurs are not excluded from the market - that is, they can start a new project by entering into a new contractual relationship - the higher value of a new project makes the repudiation option more attractive. To prevent repudiation, the value of the contract for the entrepreneur must increase. By increasing this value, the tightness of the incentive-compatibility constraint is relaxed and more capital is given to the firm. Notice that this mechanism depends crucially on the assumption that defaulting entrepreneurs are not excluded from the market. With market exclusion - which we interpret as a higher degree of contract enforcement - the investment boom of constrained firms would not arise and the economy would display lower aggregate volatility.

The result that countries with lower enforceability of contracts display greater aggregate volatility is consistent with the pattern shown in Figure 1. This figure relates the standard deviation of per-capita GDP growth to an index of contract enforceability for a cross-section of countries. This index is compiled by Business Environmental Risk Intelligence and measures "the relative degree to which contractual agreements are honored and the degree of complications presented by language and mentality differences". (See Knack and Keefer (1995)). It takes a value between 0 and 4, with higher scores for 
superior quality. The data is the average over the period 1980-95 as reported in Demirgüç-Kunt and Levine (2001) and it is available for 44 countries. The standard deviation of growth is computed using data from the World Bank Statistical Indicators for the period 1980-2001. As can be seen from the figure, there is a strong negative association between the aggregate volatility of a country and the degree of contract enforcement. ${ }^{2}$ These results are robust to alternative indexes of contract enforceability as the ones reported in Djankov, La Porta, Lopez-de-Silanes and Shleifer (2003).

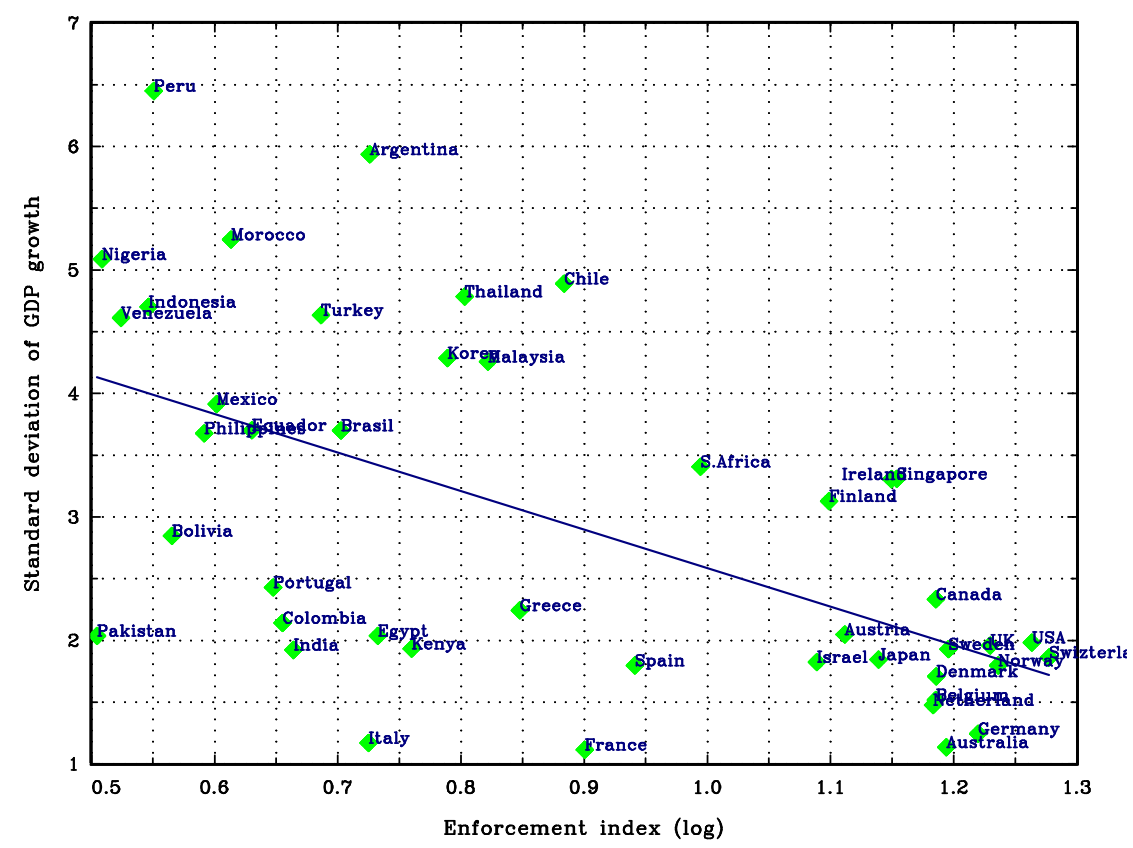

Figure 1: Correlation of contract enforcement and aggregate volatility.

Many other authors have studied the possibility that financial market frictions may amplify and propagate shocks to the economy. An important

\footnotetext{
${ }^{2}$ The correlation is -0.57 . This negative association remains significant even if we take into account the development stage of a country. We regressed our volatility index (standard deviation of GDP growth) on the log of per-capita GDP and on the log of the enforcement index. The regression results, with standard errors between parenthesis, are:

$$
\text { StdGrow }=5.84-0.02 \cdot \text { CapGDP }-2.73 \cdot \text { Enforce }, \quad \mathrm{R}^{2}=0.33
$$$$
\text { (1.91) (0.31) }
$$ 
contribution is the paper by Kiyotaki and Moore (1997). ${ }^{3}$ The key feature of this paper is the use of the firm's assets to collateralize the loan. Although collateralized debt is the typical form of financing for certain firms, for other firms it is not available simply because their assets are not very valuable outside the firm. High tech firms are an example. For firms like these the investors have to rely on direct contractual incentives rather than collateral. The optimal incentive structure then requires that the repayments to the investor are state-contingent. The state-contingency nature of the financial contract is one of the features that differentiates our model from Kiyotaki and Moore and is crucial to generating the amplification result.

Our paper also differs from Kiyotaki and Moore (1997) quantitatively, that is, in the ability to generate large amplification of shocks. Kocherlakota (2000) shows that models with credit constraint mechanisms like that in Kiyotaki and Moore cannot generate large amplification for realistic parameter values. A similar conclusion is reached by Cordoba and Ripoll (2002). This is in contrast to our quantitative results that will be shown in Section 4 .

The organization of the paper is as follows. Section 2 describes the model. Sections 3 and 4 characterize the optimal contract and define the general equilibrium. Section 5 studies the quantitative properties of the model. Section 6 summarizes and concludes.

\section{The model}

Preferences and skills: There are two types of agents: "entrepreneurs" and "workers". The mass of entrepreneurs is 1 and of workers is $m$. Workers are infinitely lived and maximize the lifetime utility:

$$
E_{0} \sum_{t=0}^{\infty}\left(\frac{1}{1+r}\right)^{t}\left(c_{t}-\varphi\left(l_{t}\right)\right)
$$

where $r$ is the intertemporal discount rate, $c_{t}$ is consumption, $l_{t}$ are working hours and $\varphi\left(l_{t}\right)$ is the disutility from working with $\varphi(0)=0, \varphi^{\prime}(l)>0$, $\varphi^{\prime \prime}(l)>0$. Given $w_{t}$ the wage rate, the supply of labor is determined by the condition $\varphi^{\prime}\left(l_{t}\right)=w_{t}$.

The life span of entrepreneurs is uncertain as they die with probability $\alpha$. New entrepreneurs are born in every period so that the mass of active

\footnotetext{
${ }^{3}$ Other recent contributions are Bernanke, Gertler and Gilchrist (1998), Carlstrom and Fuerst (1997), DenHaan, Ramey and Watson (1998), Smith and Wang (1999)
} 
entrepreneurs remains constant. The lifetime utility of an entrepreneur is:

$$
E_{0} \sum_{t=0}^{\infty}\left(\frac{1-\alpha}{1+r}\right)^{t} c_{t}
$$

Entrepreneurs have the same intertemporal discount rate as workers but they discount future consumption more heavily due to the uncertain survival. The assumption of stochastic death allows us to structure the model so that new firms are started only by newborn entrepreneurs. This simplifies the analysis because we do not need to keep track of the whole distribution of assets among potential entrants.

Technology and shocks: Entrepreneurs have the managerial ability to run an investment project. A project requires a initial fixed set-up investment $I_{0}$, which is sunk. After the initial set-up investment, it generates the gross revenue $F(z ; k, l)=z \cdot f(k, l)$. The variables $k$ and $l$ are the inputs of capital and labor, and $z$ is the project-specific productivity parameter. The function $f$ is strictly increasing in both arguments, strictly concave and satisfies $f(k, 0)=f(0, l)=0$. The input of capital is chosen one period in advance and depreciates at rate $\delta$.

The productivity parameter $z$ is project-specific, and therefore, it remains constant for a particular project. There are two types of projects: low productivity projects with $z=z_{L}$ and high productivity projects with $z=z_{H}$, where $z_{L}<z_{H}$. If a firm wants to get a different $z$, it has to invest in a new project. But this implies the loss of the previous set-up investment $I_{0}$. Therefore, if the difference between $z_{L}$ and $z_{H}$ is not too large, the replacement of an active project is never efficient. Throughout this paper we assume that this difference is sufficiently small that the net gain from replacing a $z_{L}$ project with a $z_{H}$ project is always smaller than the set-up investment $I_{0}$. This assumption will be convenient for the subsequent characterization of the optimal contract.

Before committing to the set-up investment $I_{0}$, high productivity projects are always preferable to low productivity projects. However, they are available in limited supply. We denote by $N_{t}$ the number of high productivity projects that can be started in period $t$. Given $S_{t}$ the number of searching entrepreneurs, the probability of finding a high productivity project is $p_{t}=\min \left\{N_{t} / S_{t}, 1\right\}$.

The arrival of a new technology creates better investment opportunities by increasing $N_{t}$. In this economy expansions are driven by the arrival of 
more productive projects rather than the improvement of existing ones. In this sense, the economy has the typical features of a model with vintage capital. ${ }^{4}$ The variable $N_{t}$ follows some stochastic process with probability distribution $\Gamma\left(N_{t+1}, N_{t}\right)$. In the simulation section we will consider several specifications of this function.

Entrepreneurial skills fully depreciate if the entrepreneur remains inactive. This implies that, as long as the net present value of a new project is positive, newborn entrepreneurs always undertake a project, even if they were unable to find a high productivity project. This assumption eliminates the possibility that entrepreneurs remain inactive and wait for better investment opportunities. At the same time, by undertaking a project, an entrepreneur maintains the ability to start new projects in future periods.

Financial contract and repudiation: Entrepreneurs finance the investment projects by signing long-term contracts with a financial intermediary. Contracts are not fully enforceable. In case of repudiation the entrepreneur can divert the capital $k_{t-1}$ invested in the pervious period. Diversion generates a private benefit which is equal to the amount of capital diverted. In addition, he can also start a new project by entering into a new contractual relationship. The diverted capital, however, cannot be reinvested in the new project and repudiation also carries with it a cost $\kappa .^{5}$

Denote by $\bar{V}\left(\mathbf{s}_{t}\right)$ the value of searching for a new project for the entrepreneur, where $\mathbf{s}_{t}$ denotes the aggregate states of the economy at time $t$. This function is endogenous in the model and will be derived in Section 4. For the moment, however, let's assume that this function is exogenous and known. The value of repudiating an active contract is:

$$
D\left(k_{t-1}, \mathbf{s}_{t}\right)=k_{t-1}+\bar{V}\left(\mathbf{s}_{t}\right)-\kappa
$$

The repudiation value has three components: (i) the value of diverting the capital invested in the previous period, $k_{t-1}$; (ii) the external value of searching for a new project, $\bar{V}\left(\mathbf{s}_{t}\right)$; (iii) the repudiation cost, $\kappa$. The first and

\footnotetext{
${ }^{4}$ The model is a parsimonious representation of a more complex environment in which there is persistent growth. Once we interpret the model as a detrended version of a model with persistent growth, a fall in $N_{t}$ does not necessarily imply a fall in the economy-wide productivity but only lower growth.

${ }^{5}$ Allowing for the reinvestment of the diverted capital would complicate the analysis because the value of searching for a new project would depend on this capital.
} 
second components are especially important for our results. As we will see later in the paper, without the first component all firms will operate at the optimal scale and the possibility of repudiation would play no role in the transmission of shocks. Without the second component, which corresponds to the case of market exclusion, the investment of constrained firms will not be very sensitive to shocks and we would not have the amplification result. The third component, i.e. the repudiation cost, is introduced to insure that the participation constraint for the financial intermediary is satisfied: in the absence of this cost, the repudiation value might be so large that the financial intermediary does not break even for any initial value of $k$. Finally, we should observe that the case of full enforceability is simply the case in which $D\left(k_{t-1}, \mathbf{s}_{t}\right)=0$.

Timing summary: Before continuing, it is useful to summarize the timing of the model. When a new entrepreneur is born, he searches for a high productivity project. Given the found project - characterized by the productivity parameter $z$-he will sign a long-term contract with a financial intermediary. The contract provides the funds for the initial set-up investment $I_{0}$ and the initial variable capital $k_{t}$. At the beginning of the next period then, conditional on survival, the entrepreneur observes $N_{t+1}$ and decides whether to repudiate the contract and search for a new investment project. In case of repudiation the old project is permanently lost. If instead the contract is not repudiated, the firm hires labor and production takes place. The revenues from production, net of the labor cost, are used to make payments to the entrepreneur, the financial intermediary and to finance the new variable capital $k_{t+1}$.

The firm's expected profits: For the analysis that follows it is convenient to define the discounted expected net profits generated by the period $t$ investment. These profits are given by:

$$
\begin{gathered}
\pi\left(z ; k_{t}, l_{t+1}, w_{t+1}\right)=-k_{t}+ \\
\left(\frac{1}{1+r}\right)\left\{\alpha \cdot k_{t}+(1-\alpha) \cdot\left[(1-\delta) k_{t}+F\left(z ; k_{t}, l_{t+1}\right)-w_{t+1} l_{t+1}\right]\right\}
\end{gathered}
$$

At the end of period $t$, the firm invests $k_{t}$, which is a cost, and in the next period it recovers a value which is conditional on survival. If the firm is liquidated, which happens with probability $\alpha$, the liquidation value is $k_{t}$. If 
the firm is not liquidated, production takes place and the value is $(1-\delta) k_{t}+$ $F\left(z ; k_{t}, l_{t+1}\right)-w_{t+1} l_{t+1}$.

\section{The optimal financial contract}

Assuming competition in financial markets, the optimal contract maximizes the expected discounted payments to the entrepreneur (the entrepreneur's value) subject to the enforcement constraints and the initial participation constraint for the intermediary. Consider a new contract signed at time $t$ by an entrepreneur with a project of quality $z$. Denoting by $d_{\tau}$ the payments received by the entrepreneur at time $\tau \geq t$, the contractual problem is:

$$
\begin{aligned}
V\left(z ; \mathbf{s}_{t}\right)= & \max _{\left\{d_{\tau}, k_{\tau}, l_{\tau+1}\right\}_{\tau=t}^{\infty}} E_{t} \sum_{\tau=t}^{\infty} \beta^{\tau-t} d_{\tau} \\
& \text { subject to } \\
& E_{\tau+1} \sum_{j=\tau+1}^{\infty} \beta^{j-\tau-1} d_{j} \geq D\left(k_{\tau}, \mathbf{s}_{\tau+1}\right), \quad \text { for } \tau \geq t \\
& E_{t} \sum_{\tau=t}^{\infty} \beta^{\tau-t}\left[\pi\left(z ; k_{\tau}, l_{\tau+1}, w_{\tau+1}\right)-d_{\tau}\right] \geq I_{0} \\
& d_{\tau} \geq 0
\end{aligned}
$$

Notice that the entrepreneur's payments are discounted by $\beta=(1-$ $\alpha) /(1+r)$-rather than $1 /(1+r)$-because the entrepreneur (and the firm) survives to the next period with probability $1-\alpha$.

Equation (6) is the enforcement constraint: at any future date, the value of continuing the contract for the entrepreneur cannot be smaller than the value of repudiating it, after the realization of the shock. The default value has been defined in equation (3). For the moment we take this function as given. We will derive it in Section 4.

Equation (7) is the participation constraint for the intermediary. This constraint imposes that the discounted expected value of payments received by the intermediary cannot be smaller than the set-up investment. The expected payment is $\pi\left(z ; k_{\tau}, l_{\tau+1}, w_{\tau+1}\right)-d_{\tau}$, that is, the expected discounted net profits minus the payment to the entrepreneur.

The last constraint (8) imposes the non-negativity of payments to the entrepreneur. This is justified by the non-negativity of consumption given 
that in equilibrium the entrepreneur does not own any assets outside the firm. The entrepreneur is not precluded from accumulating external assets. However, the outside investment never dominates the investment in the firm.

It is important to point out that in formulating the problem above we have assumed that the intermediary commits to fulfill any obligation, that is, there is one-sided commitment. However, in all parameterizations used in this paper, the assumption of one-side commitment is irrelevant because the value of the contract for the intermediary, after investment, is always non-negative. We will show this in Section 5.2.

\subsection{Recursive formulation}

After writing the above problem in Lagrangian form with $\gamma_{\tau+1}$ the Lagrange multiplier associated with the incentive compatibility constraint (6) and $\lambda_{t}$ the Lagrange multiplier for the participation constraint (7), the contractual problem can be written as a saddle-point formulation:

$$
\begin{array}{r}
\min _{\left\{\mu_{\tau+1}\right\}_{\tau=t}^{\infty}} \max _{\left\{d_{\tau}, k_{\tau}, l_{\tau+1}\right\}_{\tau=t}^{\infty}} \quad E_{t} \sum_{\tau=t}^{\infty} \beta^{\tau-t}\left[\pi\left(z ; k_{\tau}, l_{\tau+1}, w_{\tau+1}\right)-\left(1-\mu_{\tau}\right) d_{\tau}\right. \\
\left.-\left(\mu_{\tau+1}-\mu_{\tau}\right) \beta D\left(k_{\tau}, \mathbf{s}_{\tau+1}\right)\right]
\end{array}
$$

subject to

$$
\begin{aligned}
& \mu_{\tau+1}=\mu_{\tau}+\gamma_{\tau+1} / \lambda_{t} \\
& d_{\tau} \geq 0, \quad \mu_{t}=1 / \lambda_{t}
\end{aligned}
$$

The formal derivation of the saddle-point formulation is provided in Appendix A.1. By Theorem 1 in Marcet and Marimon (1997), a solution to the saddle point problem is a solution to the original problem. Of particular interest is the co-state variable $\mu$ that evolves according to $\mu_{\tau+1}=\mu_{\tau}+\gamma_{\tau+1} / \lambda_{t}$ for all $\tau \geq t$. This variable increases when the Lagrange multiplier $\gamma_{\tau+1}$ is positive, that is, when the enforcement constraint (6) is binding, until it reaches the value of 1 .

Notice that $\mu_{\tau}$ cannot be greater than 1. Otherwise, the objective (9) would be optimized by choosing infinitely large values of $d_{\tau}$. But this would violate the participation constraint for the intermediary. Therefore, the maximum initial value of the costate is $\mu_{t}=1$. In this case the contract simply 
maximizes the unconstrained expected discounted value of profits. However, if the participation constraint for the intermediary is tighter, then $\mu_{t}$ must be smaller than 1. As we will see in the next section, this implies that the investment of the firm is initially constrained.

Using the formulation above, we can rewrite the problem recursively as:

$$
\begin{aligned}
W(z ; \mathbf{s}, \mu)= & \min _{\mu\left(\mathbf{s}^{\prime}\right)} \max _{d, k, l^{\prime}}\left\{\pi\left(z ; k, l^{\prime}, w^{\prime}\right)-(1-\mu) d\right. \\
& \left.\quad-\beta E\left(\mu\left(\mathbf{s}^{\prime}\right)-\mu\right) D\left(z ; k, \mathbf{s}^{\prime}\right)+\beta E W\left(z ; \mathbf{s}^{\prime}, \mu\left(\mathbf{s}^{\prime}\right)\right)\right\}
\end{aligned}
$$

subject to

$$
\begin{aligned}
& d \geq 0, \quad \mu\left(\mathbf{s}^{\prime}\right) \geq \mu \\
& \mathbf{s}^{\prime} \sim H(\mathbf{s})
\end{aligned}
$$

where the prime denotes the next period variable and $H(\mathbf{s})$ is the distribution function for the next period aggregate states (law of motion). The aggregate states are given by the number of new investment projects with high productivity, $N$, and by the distribution (measure) of firms over the variables $z$ and $\mu$, which we denote by $\mathcal{M}(z, \mu)$. Therefore, $\mathbf{s}=(N, \mathcal{M})$. Notice that the choice of the next period $\mu$ is state contingent.

Before continuing, it would be useful to emphasize the connection between the original problem (5) and the recursive formulation (12). The recursive problem is equivalent to the original problem if $\mu_{t}=1 / \lambda_{t}$, where $\lambda_{t}$ is the Lagrange multiplier associated with the participation constraint for the intermediary (Equation (7)). Operationally, the initial $\mu_{t}$-and therefore $\lambda_{t}$-is determined as the value that maximizes the value of the contract for the entrepreneur subject to the participation constraint for the intermediary. The values of the contract for the entrepreneur and the intermediary can be easily computed once we have characterized the optimal contract. The two contract values are simply the expected discounted payments that the entrepreneur and the intermediary will receive from the contract, which in turn depend on the initial state $\mu_{t}$. 


\subsection{Characterization of the optimal contract}

Conditional on the survival of the firm, the solution to the optimal contract is characterized by the following first order conditions:

$$
\begin{aligned}
\mu\left(\mathbf{s}^{\prime}\right): & D\left(k, \mathbf{s}^{\prime}\right) \leq W_{\mu}\left(z ; \mathbf{s}^{\prime}, \mu\left(\mathbf{s}^{\prime}\right)\right), \quad\left(=\text { if } \mu\left(\mathbf{s}^{\prime}\right)>\mu\right) \\
d: & \mu \leq 1, \quad(=\text { if } d>0) \\
k: & \pi_{k}\left(z ; k, l^{\prime}, w^{\prime}\right)=\beta E\left(\mu\left(\mathbf{s}^{\prime}\right)-\mu\right) \\
l^{\prime}: & \pi_{l}\left(z ; k, l^{\prime}, w^{\prime}\right)=0
\end{aligned}
$$

with the envelope condition:

$$
W_{\mu}(z ; \mathbf{s}, \mu)= \begin{cases}d+\beta E D\left(k, \mathbf{s}^{\prime}\right), & \text { if } \mu\left(\mathbf{s}^{\prime}\right)>\mu \\ d+\beta E W_{\mu}\left(z ; \mathbf{s}^{\prime}, \mu\right), & \text { if } \mu\left(\mathbf{s}^{\prime}\right)=\mu\end{cases}
$$

Condition (15) is simply the enforcement constraint for which the repudiation value $D\left(k, \mathbf{s}^{\prime}\right)$ cannot be larger than the contract value for the entrepreneur $W_{\mu}\left(z ; \mathbf{s}^{\prime}, \mu\left(\mathbf{s}^{\prime}\right)\right)$. To show that $W_{\mu}\left(z ; \mathbf{s}^{\prime}, \mu\left(\mathbf{s}^{\prime}\right)\right)$ is the value of the contract for the entrepreneur, consider the case in which $\mu\left(\mathbf{s}^{\prime}\right)>\mu$. In this case condition (15) is satisfied with equality, that is, $D\left(k, \mathbf{s}^{\prime}\right)=$ $W_{\mu}\left(z ; \mathbf{s}^{\prime}, \mu\left(\mathbf{s}^{\prime}\right)\right)$. If we use this equation to eliminate $D\left(k, \mathbf{s}^{\prime}\right)$ in the envelope condition (19) we get:

$$
W_{\mu}(z ; \mathbf{s}, \mu)=d+\beta E W_{\mu}\left(z ; \mathbf{s}^{\prime}, \mu\left(\mathbf{s}^{\prime}\right)\right)
$$

This is a recursive formulation with the current flow return equal to the entrepreneur's payment. Therefore, $W_{\mu}(z ; \mathbf{s}, \mu)$ is the value of the contract for the entrepreneur given the state $\mu$ (and the aggregate state $\mathbf{s}$ ).

Condition (16) tells us that the entrepreneur receives zero payments until the state $\mu$ reaches the value of 1 . Conditions (17) and (18) determine the inputs of capital and labor. While the input of labor is always at the optimal level, that is, the marginal revenue is equalized to zero (see condition (18)), the input of capital may be smaller than the optimal level if the term $E\left(\mu\left(\mathbf{s}^{\prime}\right)-\mu\right)$ is positive (see condition (17)). This will be the case if $\mu<1$. 
Life-time dynamics of the firm: The dynamics of a firm-characterized by conditions (15)-(18) - can be described as follows. Consider a new firm created at time $t$. This firm starts with an initial state $\mu_{t}<1$. This initial state is such that the participation constraint for the investor-condition (7) in the original problem - is satisfied. More specifically, the initial state will be the maximum value of $\mu_{t}$ such that the value of the contract for the intermediary is equal to $I_{0}$. Over time, the value of $\mu$ increases in those contingencies for which the enforcement constraint is binding until it reaches 1. Before that, the entrepreneur receives zero payments and operates at a sub-optimal scale, that is, the marginal revenue from capital, $\pi_{k}$, is greater than zero. Once $\mu$ reaches the value of 1 , the input of capital is kept at the optimal level and the firm is financially unconstrained. At this point the entrepreneur starts receiving payments. However, only the expected lifetime payments are determined. Due to the linearity of preferences, the entrepreneur is indifferent on the time allocation of consumption.

The postponement of the entrepreneur's payments before the firm becomes unconstrained has a simple intuition. Because the input of capital is constrained by the entrepreneur's value (see condition (15)), an increase in this value relaxes the investment constraints of the firm. Therefore, it is optimal to postpone the entrepreneur's payments in order to relax these constraints. $^{6}$

When contracts are fully enforceable, new firms will start with $\mu=1$ and operate at the optimal scale from the beginning. In fact, because the enforceability constraint never binds, the initial $\mu$ remains constant, that is, $\mu\left(\mathbf{s}^{\prime}\right)=\mu=1 / \lambda_{t}$. This implies that $E\left(\mu\left(\mathbf{s}^{\prime}\right)-\mu\right)=0$ and (17) becomes $\pi_{k}\left(z ; k, l^{\prime}, w^{\prime}\right)=0$. Condition (16) then implies that the initial $\mu$ must be equal to 1 , otherwise the entrepreneur will never receive any payment. We summarize the dynamic properties of a firm as follows:

Firm's dynamics: When contracts are fully enforceable, all firms operate at the optimal scale $\bar{k}(z ; \mathbf{s})$. With limited enforceability, however, firms are initially small and grow on average until they reach the optimal scale. Before reaching the optimal scale the entrepreneur's payments (and consumption)

\footnotetext{
${ }^{6}$ This property derives from the assumption of risk neutrality and is common to models with financial market frictions such as Albuquerque and Hopenhayn (1997), Cooley and Quadrini (2001) and Quadrini (1999). With risk averse agents, as in Marcet and Marimon (1992), $d$ could be positive also in the constrained status. However, the motive for consumption smoothing does not completely eliminate the incentive for higher savings. See Cagetti and De Nardi (2002) and Quadrini (2000).
} 
are zero. At each point in time the economy is then characterized by two types of firms: constrained young firms and unconstrained old firms.

At the micro level, the properties of the model are similar to the properties of the partial equilibrium model of Marcet and Marimon (1992). At the aggregate level, however, our results are new as we will see in Section 5.

\section{Repudiation value and general equilibrium}

Until this point we have taken as given the repudiation function $D\left(k_{-1}, \mathbf{s}\right)=$ $k_{-1}+\bar{V}(\mathbf{s})-\kappa$, where $k_{-1}$ denotes the capital chosen in the previous period and available in the current period. Although the capital input is chosen within the contract, the value of searching for a new project $\bar{V}(\mathbf{s})$ is endogenous and depends on all the general equilibrium conditions. This function results from:

$$
\bar{V}(\mathbf{s})=(1-p) \cdot V\left(z_{L} ; \mathbf{s}\right)+p \cdot V\left(z_{H} ; \mathbf{s}\right)
$$

The variable $p=\min \{N / S, 1\}$ is the probability of finding the high productivity project which depends on the availability of these projects, $N$, and on the number of searching entrepreneurs, $S$. Because in equilibrium only newborn entrepreneurs will search for a high productive project, the number of searchers is $S=\alpha$. The function $V(z ; \mathbf{s})$ is the value of a new investment project with productivity $z$ as defined in (5).

To solve for the equilibrium we have to solve a non-trivial fixed point problem. In general we can think of this fixed point as the solution to a mapping $T$ that maps a set of functions $\bar{V}(\mathbf{s})$ into itself, that is,

$$
\bar{V}^{j+1}(\mathbf{s})=T\left(\bar{V}^{j}\right)(\mathbf{s})
$$

Given $\bar{V}^{j}$ (s) the function that determines the values of searching for new projects in all future periods, $T$ returns the value of searching for a new project today $\bar{V}^{j+1}(\mathbf{s})$. The definition of a general equilibrium follows:

Definition 4.1 (Recursive equilibrium) A recursive competitive equilibrium is defined as a set of functions for (i) labor supply $l(\mathbf{s})$ and consumption $c(\mathbf{s})$ from workers; (ii) contract policies $d(z ; \mathbf{s}, \mu), k(z ; \mathbf{s}, \mu)$ and $\mu\left(z ; \mathbf{s}, \mu, \mathbf{s}^{\prime}\right)$; (iii) initial contract state $\mu_{0}(z ; \mathbf{s})$; (iv) value of searching $\bar{V}(\mathbf{s})(v)$ wage $w(\mathbf{s})$; (vi) law of motion for the states $\mathbf{s}^{\prime} \sim H(\mathbf{s})$; and (vii) mapping T. Such that: 
(i) the consumption and labor supply from workers are optimal; (ii) the contract policies satisfy the optimality conditions (15)-(18); (iii) the initial state $\mu_{0}(z ; \mathbf{s})$ is such that the intermediary breaks even; (vi) the wage clears the labor market; (v) the capital market clears (investment equals savings); (vi) the function $H(\mathbf{s})$ is consistent with individual decisions and the shock; (vii) the searching value $\bar{V}(\mathbf{s})$ is the fixed point of $T$.

Proving the existence of an equilibrium requires the proof of the existence of a fixed point in (22). This is a difficult task because $\bar{V}(\mathbf{s})$ is a function of the whole distribution of firms. However, the existence and uniqueness of a steady state equilibrium can be easily established. This is formally stated in the next proposition.

Proposition 4.1 Assume that $z_{L}=z_{H}$. Then there exists a unique steadystate equilibrium characterized by an invariant distribution of firms and constant values of $\bar{V}(\mathbf{s})$ and $w(\mathbf{s})$.

Proof 4.1 Appendix A.2.

\section{Contrasting economies with and without contract enforceability}

In this section we study the properties of the model using a parameterized version of the model. Section 5.1 describes the parameterization and Section 5.2 shows some of the dynamic properties of an individual firm in the steady state equilibrium. Section 5.3 studies the response of the aggregate economy to shocks and Section 5.4 quantifies the welfare losses associated with limited contract enforceability.

\subsection{Parameterization}

We calibrate the economy using steady state values for the deterministic version of the economy with $z_{L}=z_{H}=\bar{z}$. The period in the economy is one year and the intertemporal discount rate, which is equal to the interest rate, is set to $r=0.04$. The disutility from working takes the form $\varphi(l)=A \cdot l^{\frac{1+\epsilon}{\epsilon}}$, where $\epsilon$ is the elasticity of labor. In the baseline model we set $\epsilon=1$ which is the value often used in business cycle studies. We will also report the results 
for alternative values of $\epsilon$. The parameter $A$ is chosen so that one third of available time is spent working.

The mass of workers $m$ coincides with the average employment size of firms because the mass of entrepreneurs is 1 . Given that the parameter $A$ is chosen so that $l=0.33$, higher values of $m$ imply lower values of the wage rate but do not affect the properties of the model.

The death probability of entrepreneurs, which in the model corresponds to the exit rate of firms, is set to $\alpha=0.05$. This is consistent with the numbers reported in industry dynamics studies such as Evans (1987). ${ }^{7}$

The production function is specified as $z \cdot\left(k^{\nu} l^{1-\nu}\right)^{\theta}$. Based on the discussion in Atkeson, Khan and Ohanian (1996) we set $\theta=0.85$. This is also the value used by Atkeson and Kehoe (2001). After fixing $\theta$, the parameter $\nu$ is set so that the labor income share of unconstrained firms is 0.6. For unconstrained firms the labor share is equal to $\theta(1-\nu)$. Given $\theta=0.85$, this implies a value of $\nu=0.294$. Because in the economy there are also constrained firms, the economy-wide labor share is not exactly 0.6. However, because a large portion of aggregate production is generated by unconstrained firms, the economy-wide share of labor income is not very different from 0.6. A similar idea is used to calibrate $\delta$. Using the first order condition for the optimal input of capital $\pi_{k}=0$ (which is satisfied for unconstrained firms), the depreciation rate can be expressed as $\delta=\frac{\theta \nu}{K / Y}-\frac{r}{1-\alpha}$. With a capitaloutput ratio of 2.5 and the values of the other parameters chosen above, we get $\delta=0.0579$. The value of $\bar{z}$ is chosen such that the input of capital of unconstrained firms is equal to 1 . This is just a normalization.

Given the parameterization of the production sector, the model generates a stationary distribution of firms. The initial set-up investment $I_{0}$ and the repudiation cost $\kappa$ affect the initial size of new firms which in turn affects the fraction of firms that are constrained. More specifically, when $I_{0}$ is large and $\kappa$ is small, the initial size of new firms is smaller and the fraction of constrained firms larger. We parameterize $I_{0}$ and $\kappa$ so that in the steady state 40 percent of firms are constrained. Although there are not direct indicators of how many firms find their investment plans constrained by financial considerations, the 40 percent target seems reasonable. The sensitivity analysis will then show how the magnitude of the amplification result is affected by

\footnotetext{
${ }^{7}$ The entrepreneurs' death should not be interpreted only as biological death. It also includes the loss of entrepreneurial skills. Once we assign this broader interpretation, the 5 percent probability is not unreasonable.
} 
the choice of this particular parameterization target.

Notice that the parameterization target for the number of constrained firms can be reached with different combinations of $I_{0}$ and $\kappa$. However, the particular choice of these two parameters do not affect significantly the quantitative results as long as they lead to the same fraction of constrained firms. We assume $I_{0}=0.2$ and $\kappa=0.35$. This implies that the set up and repudiation costs are 20 and 35 percent the value of variable capital used by unconstrained firms (which we have normalized to 1 ). These values can be considered a compromise given the constraints we face in the choice of these two parameters. ${ }^{8}$

The last part of the model that need to be parameterized is the productivity differential between low and high projects - that is, $z_{L}$ and $z_{H}$-and the probability distribution for the arrival of high productivity projects $N$. This will depend on the particular exercise we conduct when we study the response of the aggregate economy to the arrival of a new technology. We will choose these parameters in Section 5.3 when we describe these exercises. The full set of parameter values are reported in Table 1.

Table 1: Parameter values.

\begin{tabular}{ll}
\hline \hline & \\
Intertemporal discount rate & $r=0.04$ \\
Disutility from working $\varphi(l) \equiv A \cdot l^{\frac{1+\epsilon}{\epsilon}}$ & $A=0.001, \epsilon=1$ \\
Death probability of entrepreneurs & $\alpha=0.05$ \\
Production technology $\bar{z} \cdot\left(k^{\nu} l^{1-\nu}\right)^{\theta}$ & $\bar{z}=0.012, \theta=0.85, \nu=0.294$ \\
Depreciation rate & $\delta=0.0579$ \\
Set-up investment & $I_{0}=0.2$ \\
Cost of repudiation & $\kappa=0.35$ \\
& \\
\hline
\end{tabular}

\section{$5.2 \quad$ Steady state properties}

Before studying the response of the economy to the arrival of new technologies, it is instructive to examine some features of the optimal contract when

${ }^{8}$ If $I_{0}$ is too small, active firms with low productivity projects would always find convenient to replace them with high productivity projects. If $I_{0}$ is too large, low productivity projects would never be implemented. If $\kappa$ is too small, then there would not be an optimal contract that satisfies the participation constraint of the intermediary (zero profit condition). If $\kappa$ is too large, contracts would be fully enforceable. 
there is no aggregate uncertainty $\left(z_{L}=z_{H}=\bar{z}\right)$ and the economy is in the steady state equilibrium. These properties will be helpful for understanding the behavior of the economy when there is aggregate uncertainty.

A new firm starts with an initial $\mu<1$. In the steady state equilibrium the next period value of $\mu$ is always greater than the current value until it reaches 1 . Therefore, equation (15) is satisfied with equality. Using the envelope condition (19) to eliminate $W_{\mu}$ and taking into account that for $\mu^{\prime}<1$ the entrepreneur's payments $d$ are zero (see condition (16)), condition (15) can be written as $D(k)=\beta D\left(k^{\prime}\right)$. We have omitted $z$ and $\mathbf{s}$ as explicit arguments of the repudiation function because in the steady state they are constant. Finally, remembering that $D(k)=k+\bar{V}-\kappa$, where $\bar{V}$ is constant in the steady state, we have:

$$
k+\bar{V}-\kappa=\beta\left(k^{\prime}+\bar{V}-\kappa\right)
$$

Given the initial capital $k_{t}$ associated with the initial $\mu_{t}$, equation (23) determines the whole life-time path of capital. This path is such that the firm starts small and grows over time until it reaches the unconstrained status with $\bar{k}$. Because in every period there is entry by new firms and exit of some incumbents, the size distribution of firms will be non-degenerate. This is in contrast to the case in which contracts are fully enforceable where all firms operate at the optimal scale from the beginning.

The invariant (steady state) distribution for the economy with full and limited enforceability are plotted in Figure 2. The hight of each bar corresponds to the fraction of firms operating with a specific input of capital (firm size). In the case of limited enforceability (plot b), each size class of firms corresponds to a particular age class with the last class including all firms older than the number of years necessary to reach the unconstrained status. For this parameterization, firms reach the unconstrained status in 10 years. In the steady state distribution, 40 percent of firms are constrained, they use 29 percent of aggregate capital and they produce 33 percent of aggregate output. Notice that the size of firms in the economy with enforceable contracts is smaller than the size of unconstrained firms in the economy with limited enforceability. This is because, for each wage rate, the aggregate demand of labor is smaller when contracts are not enforceable. In equilibrium, then, the wage rate is smaller and the optimal size of unconstrained firms is larger.

The first panel of Figure 3 plots the values of a new contract for the entrepreneur and the intermediary as a function of capital. These are the 
(a) Full enforceability

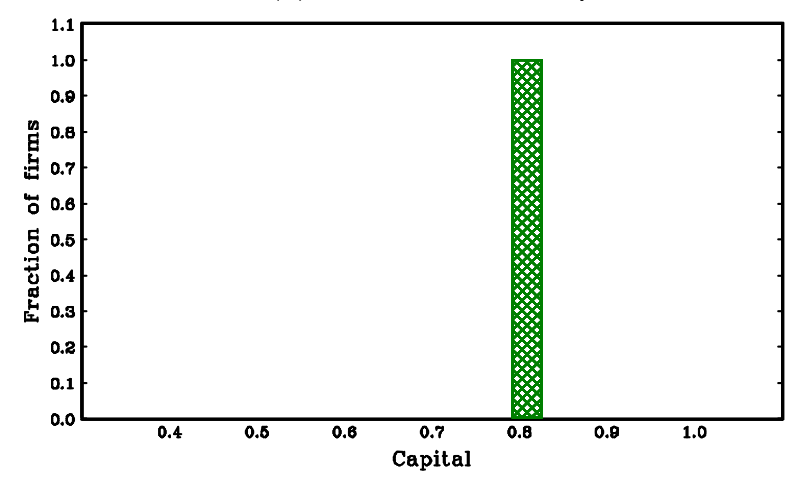

(b) Limited enforceability

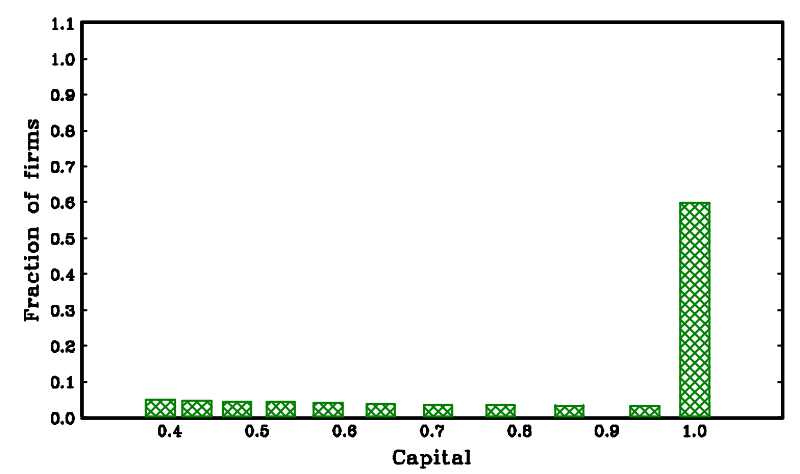

Figure 2: Steady state distribution of firms.

values $E \sum_{\tau=t}^{\infty} \beta^{\tau-t} d_{\tau}$ and $E \sum_{\tau=t}^{\infty} \beta^{\tau-t}\left[\pi\left(z ; k_{\tau}, l_{\tau+1}, w_{\tau+1}\right)-d_{\tau}\right]$. As can be seen from the figure, the entrepreneur's value increases with $k$ while the value for the intermediary decreases with $k$. The assumption of competition in financial markets then implies that the initial value of the contract for the intermediary is equal to the set-up investment $I_{0}=0.2$, that is, the participation constraint for the investor imposed in problem (5) is binding. New firms start with an input of capital that is 39 percent smaller than the unconstrained value $\bar{k}$. From Figure 3 we can also see how the set-up investment affects the initial size of new firms. When $I_{0}$ is large, the initial value of the contract for the intermediary must also be large in order for the intermediary to cover the cost of this investment. This requires that the initial size of the firm is smaller and in aggregate there will be a larger fraction of constrained firms.

After the initial entrance of the firm, the input of capital grows over time 
(a) Value of the contract before investment

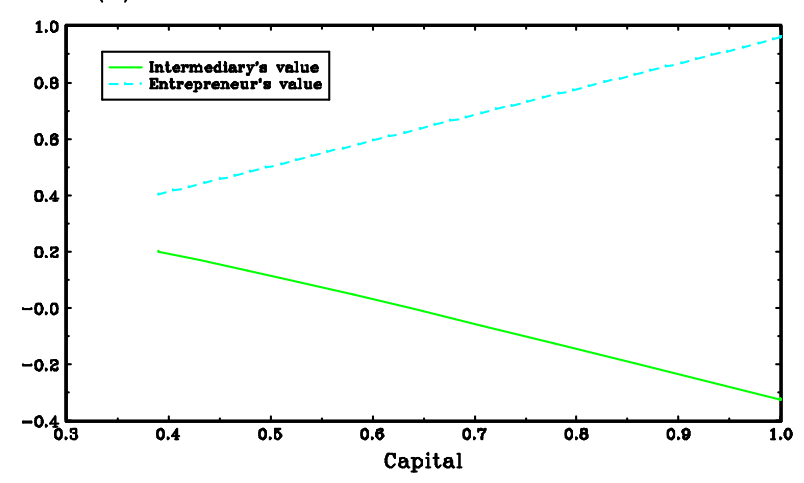

(b) Intermediary's value after investment

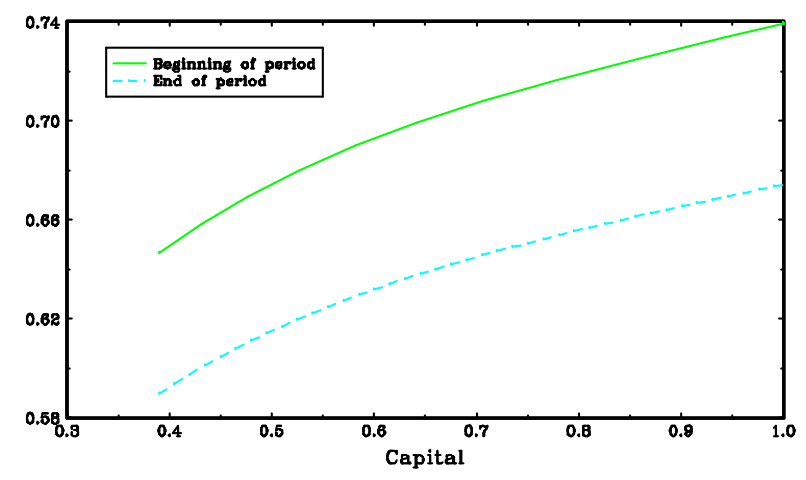

Figure 3: Steady state contract values.

and the value for the intermediary becomes negative. Notice, however, that this is the value before capital investment while for the decision to repudiate the contract what is relevant is the value after capital investment. More specifically, the intermediary could repudiate the contract at the beginning or at the end of the period. The intermediary value at the beginning of period $t$ (before receiving or making any payment) is:

$$
(1-\delta) k_{t-1}+F\left(z ; k_{t-1}, l_{t}\right)-d_{t}+E_{t} \sum_{\tau=t}^{\infty} \beta^{\tau-t}\left[\pi\left(z ; k_{\tau}, l_{\tau+1}\right)-d_{\tau}\right]
$$

The value at the end of the period (after receiving or making payments) is:

$$
k_{t}+E_{t} \sum_{\tau=t}^{\infty} \beta^{\tau-t}\left[\pi\left(z ; k_{\tau}, l_{\tau+1}\right)-d_{\tau}\right]
$$


These two values are plotted in Figure 3. The important point is that these values are always positive in the baseline model. With aggregate uncertainty they are affected by the shock but they never become negative. Therefore, the intermediary will never repudiate the contract.

\subsection{Contract enforceability and the diffusion of new technologies}

In this section we study how the economy responds to the arrival of a new technology that increases the number of high productivity projects $N_{t}$. We will consider two hypothesis about the persistence of the shock: temporary and permanent.

Temporary shocks: We first consider the case in which $N_{t}$ is independently and identically distributed as a uniform in the interval $[0, \alpha]$, where $\alpha$ is the mass of newborn entrepreneurs. The expected value of $N_{t}$ is denoted by $\bar{N}=\alpha / 2$. Because in equilibrium only newborn entrepreneurs search for a high productivity project, that is, $S_{t}=\alpha$, the probability of success $p_{t}=N_{t} / S_{t}$ is uniformly distributed in the interval $[0,1]$.

After simulating the economy for a long sequence of $N_{t}=\bar{N}$, we consider the arrival of a new technology that increases $N_{t}$ to $2 \bar{N}=\alpha$. This implies that after a long sequence of $p_{t}=0.5$, this probability increases to 1 . The increase in $N_{t}$ is only for one period and from the next period on it reverts to its mean value. The economy will then converge to the same equilibrium before the arrival of the new technology. ${ }^{9}$ In the simulation we assume that $z_{L}=0.98 \bar{z}$ and $z_{H}=1.02 \bar{z}$. The chosen productivity differential implies that high productivity projects, when operated at the optimal scale, are about 30 percent larger than low productivity projects. With this productivity differential active entrepreneurs never search for a new investment project in equilibrium. We would like to point out that, as long as the productivity differential is not too large, our propagation mechanism does not depend on the volatility of the shock. Therefore, within this limit, the parameterization of $z_{L}$ and $z_{H}$ is irrelevant for the main points we want to make in this section.

The responses of aggregate output to the arrival of the (temporary) technology are reported in Figure 4. Three versions of the economy are considered: (i) full enforceability; (ii) limited enforceability with market exclusion; (iii) limited enforceability without market exclusion. These three

\footnotetext{
${ }^{9}$ Although we solve the economy for a particular sequence of $N_{t}$, agents solve a stochastic dynamic problem where they expect future values of $N$ to be randomly distributed.
} 
cases imply different specifications of the repudiation function. In the case of full enforceability $D\left(k_{-1}, \mathbf{s}\right)=0$. In the case of limited enforceability with market exclusion $D\left(k_{-1}, \mathbf{s}\right)=k_{-1}-\kappa$. Without market exclusion $D\left(k_{-1}, \mathbf{s}\right)=k_{-1}+\bar{V}(\mathbf{s})-\kappa$. In the case of market exclusion we have changed the value of $\kappa$ so that the two versions of the model with limited enforceability have the same repudiation values in the steady state equilibrium. Therefore, the two models are indistinguishable in the steady state. ${ }^{10}$

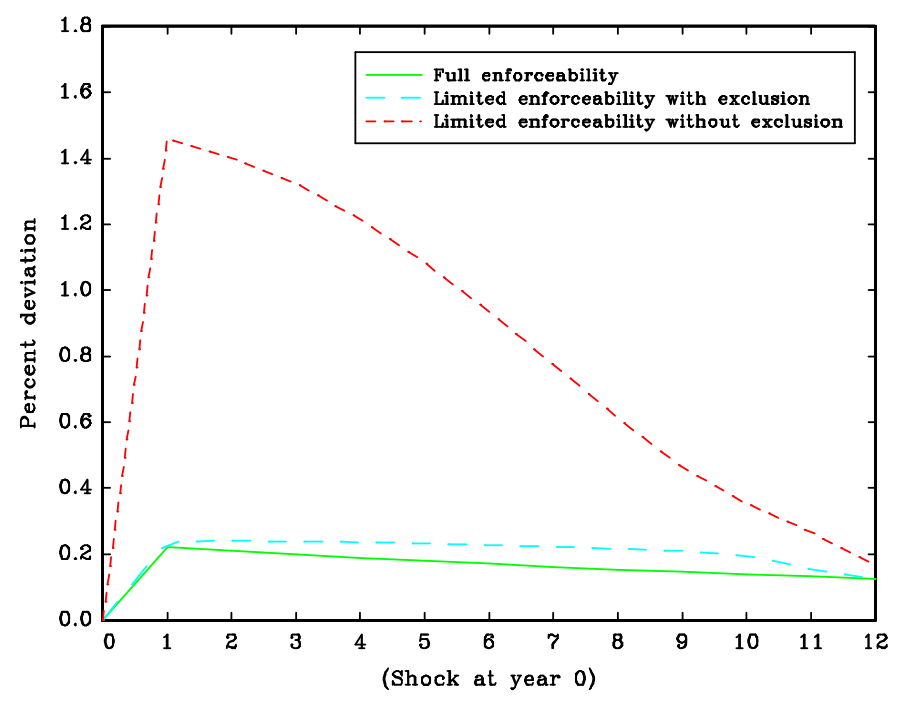

Figure 4: Output response to a temporary shock.

The figure shows two important results. First, limited contract enforceability introduces a powerful amplification mechanism: at impact, the increase in output is about 6 times bigger than in the economy with full enforceability. Second, to generate amplification, it is crucial to assume that there is no market exclusion. In fact, when repudiating entrepreneurs are excluded from the market, the response of aggregate output is not substantially different from the case of full enforceability.

We have also computed the standard deviation of aggregate output resulting from the simulation of the artificial economy. ${ }^{11}$ When contracts are

\footnotetext{
${ }^{10}$ Given $\kappa$ and the steady state value of $\bar{V}$ in the economy without market exclusion, the repudiation cost in the economy with market exclusion is set to $\kappa-\bar{V}$.

${ }^{11}$ After simulating the economy for 700 periods and discarding the first 200 data points,
} 
fully enforceable, the standard deviation is only 0.4 percent the mean value of output. With limited enforceability and no market exclusion, the standard deviation is 1.6 percent, that is, four times the value when contracts are enforceable. However, if we exclude defaulting entrepreneurs from participating in the market, this number drops to 0.45 percent, which is close to the number obtained when contracts are enforceable.

To describe the mechanism that generates amplification, let's describe first how the new technology propagates in the economy with full enforceability. In this economy the expansion of aggregate output derives in part from the increase in the productivity of old and new firms and in part from the increase in employment. The productivity of new firms increases because they implement more productive projects. The productivity of old firms increases because they reduce the scale of production after the wage increase.

The mechanism described above is also present in the economy with limited enforceability. In this economy, however, aggregate output receives an additional impulse from the expansion of constrained old firms. In fact, after the arrival of the new technology, the repudiation value for entrepreneurs of constrained firms increases. To prevent repudiation, the value promised to the entrepreneur must increase. This relaxes the tightness of the incentive compatibility constraints and more capital can be given to these firms. Therefore, the impact of the new technology is to lessen the tightness of the financial constraints.

This mechanism can be easily illustrated using the first order condition (15). For constrained firms, that is, for firms with $\mu_{-1}<1$, this condition is approximately equal to: ${ }^{12}$

$$
k_{-1}+\bar{V}(\mathbf{s})-\kappa=\beta\left[k+E \bar{V}\left(\mathbf{s}^{\prime}\right)-\kappa\right]
$$

The new technology increases the searching value $\bar{V}(\mathbf{s})=(1-p) \cdot V\left(z_{L} ; \mathbf{s}\right)+$ $p \cdot V\left(z_{H} ; \mathbf{s}\right)$ but, because it is temporary, it will have only a marginal impact

we computed the standard deviation of the logarithm of aggregate output. We repeated the simulation 50 times and averaged the number obtained in each of the 50 simulations.

${ }^{12}$ This condition would hold exactly if the incentive-compatibility constraint was always binding for constrained firms. This is not a bad approximation because the incentivecompatibility constraint is only occasionally non-binding. Once we make this assumption, equation (26) can be derived from (15) after we eliminate $W_{\mu}$ using the envelope condition (19) and we take into account that for $\mu^{\prime}<1$, the entrepreneur's payments $d$ are zero (see condition (16)). Finally, we replace $D\left(k_{-1}, \mathbf{s}\right)$ with $k_{-1}+\bar{V}(\mathbf{s})-\kappa$. 
on $E \bar{V}\left(\mathbf{s}^{\prime}\right)$. Therefore, the left-hand-side increases more than the right-handside. Because $k_{-1}$ is given, the new capital $k$ must increase. Figure 5 also shows that the amplification effect is very persistent. This is because the shock shifts to the right the whole distribution of constrained firms. After the shift, it takes several periods to converge back to the limiting distribution.

This mechanism is absent when there is market exclusion. In this case equation (26) becomes $k_{-1}-\kappa \leq \beta[k-\kappa]$ and the investment of the firm before it reaches the unconstrained status is independent of the shock. This feature differentiates our model from other general equilibrium models with endogenous market incompleteness where default takes the form of autarky. One exception is Phelan (1995), which however considers only steady states.

The economy with market exclusion is an economy with a higher degree of contract enforceability. In this sense, higher enforcement leads to lower macroeconomic instability. Another dimension along which we can affect the degree of contract enforceability is through the repudiation cost $\kappa$. In fact, higher values of this cost reduce the incentive to repudiate, and therefore, increase the degree of contract enforceability.

The first panel of Figure 5 plots the impulse responses to a temporary shock for different values of $\kappa$ when there is no market exclusion. As shown in the figure, higher values of $\kappa$ reduce the amplification effect described above. Therefore, the lower the degree of contract enforceability and the larger is the macro impact of new technologies.

The reason a higher value of $\kappa$ reduces the amplification effect is because in equilibrium the fraction of constrained firms is smaller and on average they are closer to the unconstrained status. This in turn derives from the fact that the initial size of new firms is larger when $\kappa$ is bigger. As a result of this, firms reach the unconstrained status faster and in each period there is a smaller fraction of constrained firms. Because the amplification effect derives from the reaction of constrained firms, smaller is their fraction and smaller is the impact of the shock on aggregate output. In the limiting equilibrium of the baseline economy, about 40 percent of firms are constrained. With the higher value of $\kappa=0.60$, only 30 percent are constrained.

The second panel of Figure 5 reports the impulse responses for alternative values of the elasticity of labor $\epsilon$. When the supply of labor is rigid (low values of $\epsilon$ ), the shock has a smaller impact on aggregate output. This is because the expansion of constrained firms is compensated by the contraction of unconstrained firms in response to a larger increase in the wage 
(a) Sensitivity to the repudiation cost

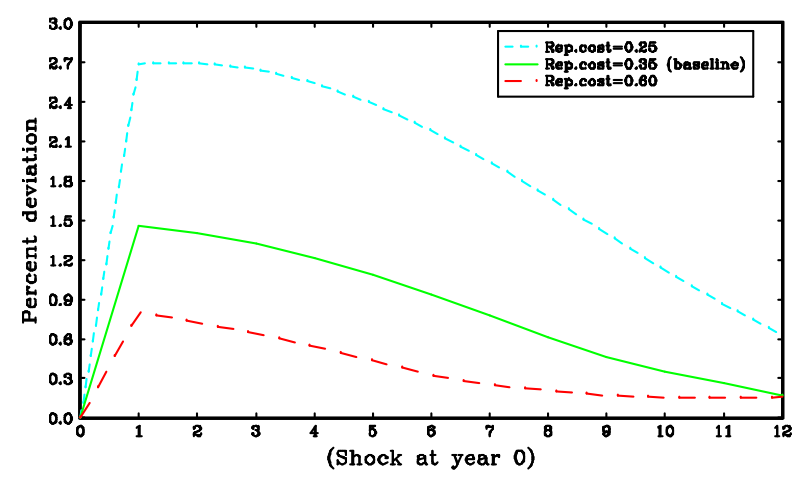

(b) Sensitivity to the elasticity of labor

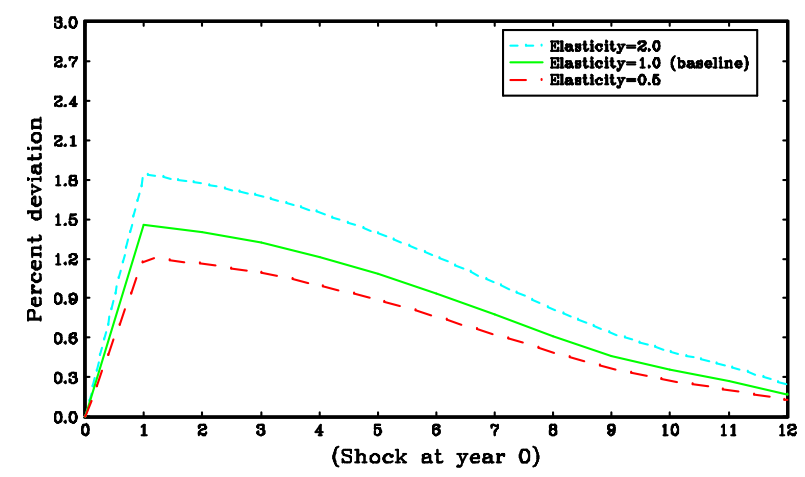

Figure 5: Sensitivity to repudiation cost and labor elasticity.

rate. However, the elasticity of labor affects the magnitude of the output response not only in the economy with limited enforceability but also in the full enforcement economy. Therefore, the magnification factor is in general independent from the elasticity of labor.

Permanent shocks: The above results are based on the assumption that the new technology increases the number of high productive projects only temporarily. A different way to think about the arrival of a new technology is when it increases the productivity of all new projects. We can think of this type of innovations as generated by new general purpose technologies.

Suppose that the economy has been in the state $N=0$ for a long period of time. Then, unexpectedly, there is the arrival of a new technology which 
increases $N$ to $\alpha$ permanently and all projects implemented during and after that period will have high productivity. Figure 6 plots the response of aggregate output for the economies with full and limited contract enforceability (without market exclusion). The two values of $z$ are as in the case of a temporary shock, that is, $z_{L}=0.98 \bar{z}$ and $z_{H}=1.02 \bar{z}^{13}$

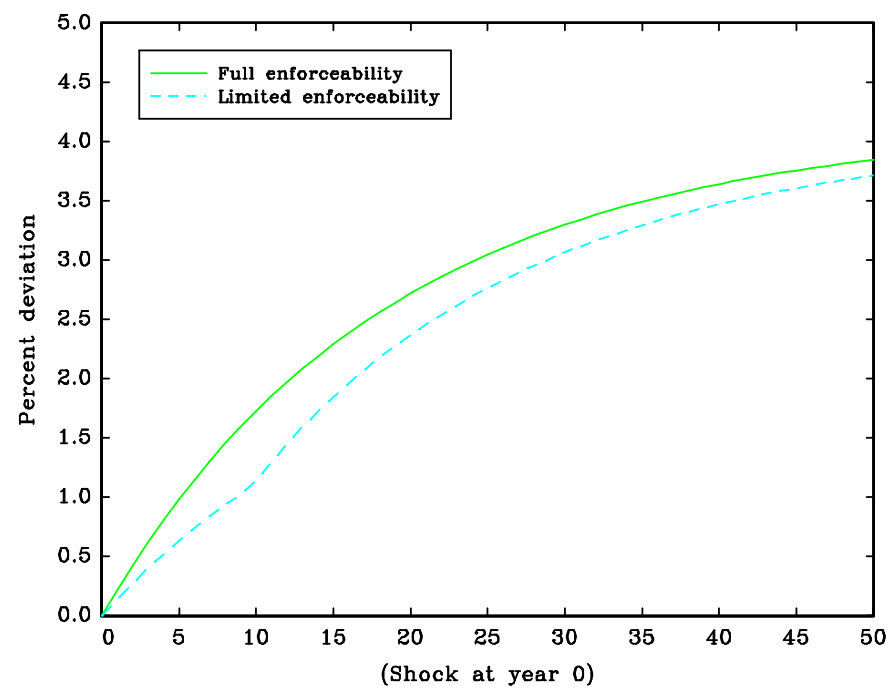

Figure 6: Output response to a permanent shock.

With limited enforceability the convergence to the higher long-run level of output is slower. Therefore, limited enforceability delays the diffusion of this type of technologies and there is no amplification. To see why the impact of this type of innovation is not amplified, consider again equation (26). This equation describes the investment behavior of constrained firms, which are the source of the amplification result shown above. As in the previous case, the new technology increases $\bar{V}(\mathbf{s})$. The difference, however, is that now the term $E \bar{V}\left(\mathbf{s}^{\prime}\right)$ also increases. Therefore, the increase in the left-hand-side is mostly compensated by the increase in the right-hand-side. As a result, the input of capital $k$ increases only modestly.

\footnotetext{
${ }^{13}$ Differently from the experiment conducted in the previous section, we now assume that agents solve a deterministic problem before and after the arrival of the new technology. Alternatively, we could have assumed that $N_{t+1}=N_{t}+\varepsilon_{t+1}$ where $\varepsilon$ is i.i.d., and agents solve a stochastic problem. This would not change significantly the quantitative properties of the impulse response.
} 
The delaying effect derives from the dynamics of new firms. After the arrival of the new technology, output increases because the new firms are more productive. However, the impact on output when contracts are not fully enforceable will be more gradual because the new firms are initially small. As these firms grow in size, the contribution of their higher productivity to aggregate output increases. In contrast, when contracts are fully enforceable, new firms start with the optimal scale from the beginning.

This result can be considered a possible explanation of why the new Information Technologies of the 1970s took a long time to display their full potential on productivity as pointed out in Greenwood and Jovanovic (1999). If we interpret the IT revolution as the permanent arrival of a new technology, our theory provides a financial explanation for its sluggish diffusion. The financial explanation complements the sluggish diffusion induced by the vintage structure of investment projects.

Our theory is also consistent with the empirical evidence about the better performance of new listed firms after the IT revolution as shown in Hobijn and Jovanovic (2001). In our model this feature derives from the vintage structure and is consistent with the view expressed in the above paper: the reason new firms outperformed incumbent firms is because they were less dependent on old technologies, and therefore, they were more flexible.

\subsection{Welfare consequences of limited contract enforceability}

In this final section we evaluate the welfare consequences of limited contract enforceability. In evaluating the welfare consequences we assume that $z_{L}=$ $z_{H}=\bar{z}$, and therefore, there is no aggregate uncertainty.

We conduct the following experiment. Starting from the steady state of the economy with limited enforceability, we assume that all contracts become enforceable (including the existing ones). This unanticipated change brings the economy to a new equilibrium in which all firms employ the same input of capital and labor. The transition takes only one period.

Table 2 reports the welfare gains from the transition to the fully enforcement economy. These gains are computed as the increase in every period consumption necessary to make all agents indifferent between staying in the economy with limited enforceability (but with the consumption increase) or making all contracts fully enforceable (and starting the transition). The table also reports the changes of some key statistics. For the baseline parameterization, the enforcement of contracts induces an increase in the supply of 
labor of almost 2 percent and an increase in aggregate output of almost 4 percent. The welfare gains are 0.46 percent of consumption.

Table 2: Welfare consequences of limited contract enforceability.

\begin{tabular}{|c|c|c|}
\hline & $\begin{array}{c}\text { Limited } \\
\text { Enforceability }\end{array}$ & $\begin{array}{c}\text { Full } \\
\text { Enforceability }\end{array}$ \\
\hline & \multicolumn{2}{|c|}{ Baseline } \\
\hline Average size of firms (capital) & \multirow[t]{4}{*}{0.848} & 0.931 \\
\hline Change in working time & & $1.82 \%$ \\
\hline Steady state output gain & & $3.84 \%$ \\
\hline \multirow[t]{2}{*}{ Welfare gain from transition } & & $0.46 \%$ \\
\hline & \multicolumn{2}{|c|}{ Low repudiation cost, $\kappa=0.25$} \\
\hline Average size of firms (capital) & \multirow[t]{4}{*}{0.794} & 0.902 \\
\hline Change in working time & & $2.73 \%$ \\
\hline Steady state output gain & & $5.40 \%$ \\
\hline \multirow[t]{2}{*}{ Welfare gain from transition } & & $0.87 \%$ \\
\hline & \multicolumn{2}{|c|}{ High repudiation cost, $\kappa=0.60$} \\
\hline Average size of firms (capital) & \multirow[t]{4}{*}{0.941} & 0.978 \\
\hline Change in working time & & $0.61 \%$ \\
\hline Steady state output gain & & $1.48 \%$ \\
\hline \multirow[t]{2}{*}{ Welfare gain from transition } & & $0.08 \%$ \\
\hline & \multicolumn{2}{|c|}{ High elasticity of labor, $\epsilon=2.0$} \\
\hline Average size of firms (capital) & \multirow[t]{4}{*}{0.848} & 0.942 \\
\hline Change in working time & & $3.33 \%$ \\
\hline Steady state output gain & & $4.91 \%$ \\
\hline \multirow[t]{2}{*}{ Welfare gain from transition } & & $0.46 \%$ \\
\hline & \multicolumn{2}{|c|}{ Low elasticity of labor, $\epsilon=0.5$} \\
\hline Average size of firms (capital) & 0.848 & 0.925 \\
\hline Change in working time & & $0.91 \%$ \\
\hline Steady state output gain & & $3.15 \%$ \\
\hline Welfare gain from transition & & $0.46 \%$ \\
\hline
\end{tabular}

Table 2 also reports the macroeconomic and welfare implications for alternative values of the repudiation cost and the elasticity of labor. As can be seen from the second and third sections, the macroeconomic and welfare implications are larger when the cost of repudiation is low. This is because in equilibrium a larger fraction of firms are constrained. For example, when $\kappa=0.25$, about 45 percent of firms are constrained, compared to 40 percent in the baseline economy. When $\kappa=0.6$, only 30 percent of firms are constrained and their size is closer to the unconstrained size. In this case 
the welfare gains are small. These welfare implications parallels the results shown in the previous sections according to which lower repudiation costs lead to greater aggregate volatility.

We also consider different values of the elasticity of labor $\epsilon$. The larger the elasticity of labor and the larger is the effect of contract enforceability on the macro allocation of resources (labor, capital and output). When the supply of labor is elastic, the increase in the demand of labor leads to a modest increase in the wage rate. Consequently, the expansion of previously constrained firms is not compensated by the contraction of unconstrained firms (after the wage increase). However, independently of the value of $\epsilon$, the welfare gains are in the order of 0.5 percent of consumption. The reason the larger increase in output and consumption do not lead to larger welfare gains is because the expansion requires higher savings in the first period of the transition, which is a cost. The welfare consequences of limited contract enforceability are also studied in Quintin (2000).

\section{Conclusion}

We have studied an economy in which entrepreneurs finance investment by entering into long-term contracts with financial intermediaries. Contracts are not fully enforceable and the incentive compatibility requirement makes investment dependent on the repudiation value of the entrepreneur, which is only binding for small and fast growing firms.

Limited enforceability has important implications for the macro-economy in two dimensions. On the one hand it impairs the efficient allocation of resources with significant welfare consequences. On the other it affects the diffusion path of new technologies or aggregate shocks. In particular, we have shown that limited enforceability creates a powerful amplification mechanism. This amplification mechanism depends on two important features of the model: the state-contingency nature of the optimal contract and the assumption that defaulting entrepreneurs are not excluded from the market. The amplification result would disappear if financial contracts were not state contingent - as in the case of standard debt contracts - or if repudiation leads to market exclusion - which is the assumption usually made in macro models with limited contract enforceability.

We have also shown that limited enforcement can delay the diffusion of certain technologies. This "delay effect" is consistent with historical evidence, not only on the diffusion of information technologies-as discussed 
by Greenwood and Jovanovic (1999) — but also in other technological revolutions, such as the diffusion of steel or electricity (see, for example, Freeman and Soete (1997)). Different factors can help to explain this pattern, such as the need to develop complementary technologies, the need for a fall in the price of the new product or simply self-interested resistance to new technology (Mokyr (2002, p.220)). In this paper we have provided an additional and complementary explanation which is based on the existence of financial frictions induced by limited contract enforceability.

An important element of our theory is that new technologies are mainly adopted by younger firms facilitated by their greater flexibility. This seems consistent with the diffusion and growth of certain industries in the Unites States such as the computer industry. For example, Bresnahan and Malerba (2002) examine how the U.S. has persistently led through the distinct eras of the computer industry. Most of the growth of the industry was due to the growth of new and small firms, not just the incumbent of the first era, IBM. Furthermore, new eras did not represent the disappearance of previous leaders, but the overall growth of the industry. This also seems to be the pattern in the expansion of information and communication technologies during the 1990s.

The results of the paper suggests several extensions. Because the limited enforceability of contracts induces a sub-optimal allocation of resources, it becomes important to understand which policies could change this allocation. The first obvious candidate is the consideration of institutional reforms leading to greater enforcement of contracts. In the model this could be formally captured by an increase in the repudiation cost $\kappa$ and/or by making difficult for repudiating entrepreneurs to sign new contracts. The effect of these reforms is to increase the initial size of new firms and in equilibrium there will be a smaller number of constrained firms. However, enforceability also depends on informal institutions that are difficult to change in a short period of time. Other policies could impact on the cost of implementing a new project. In the model this is captured by a decrease in the set-up investment $I_{0}$. A decrease in this cost would increase the initial size of new firms and would reduce the number of constrained firms. We leave for future research the study of these and other related issues. 


\section{A Appendix: Analytical proofs}

\section{A.1 Derivation of the saddle-point formulation}

Consider problem (5). Given $\gamma_{\tau+1}$ the Lagrange multiplier associated with the enforcement constraint (6) and $\lambda_{t}$ the Lagrange multiplier associated with the participation constraint (7), the Lagrangian can be written as:

$$
\begin{aligned}
\mathcal{L}=E_{t} \sum_{\tau=t}^{\infty} \beta^{\tau-t}\left\{d_{\tau}+\lambda_{t}\left[\pi\left(z ; k_{\tau}, l_{\tau+1}, w_{\tau+1}\right)-d_{\tau}\right]+\right. \\
\left.\gamma_{\tau+1} \beta\left[\sum_{j=\tau+1}^{\infty} \beta^{j-\tau-1} d_{j}-D\left(z ; k_{\tau}, \mathbf{s}_{\tau+1}\right)\right]\right\}
\end{aligned}
$$

After rearranging terms, the Lagrangian can be written as:

$$
\begin{aligned}
\mathcal{L} & =E_{t} \sum_{\tau=t}^{\infty} \beta^{\tau-t}\left\{\lambda_{t} \pi\left(z ; k_{\tau}, l_{\tau+1}, w_{\tau+1}\right)-\left(\lambda_{t}-1\right) d_{\tau}-\gamma_{\tau+1} \beta D\left(z ; k_{\tau}, \mathbf{s}_{\tau+1}\right)(28)\right. \\
& +E_{t} \sum_{\tau=t}^{\infty} \beta^{\tau-t} \gamma_{\tau+1} \sum_{j=\tau+1}^{\infty} \beta^{j-\tau} d_{j}
\end{aligned}
$$

Let 's observe now that the following identity holds:

$$
\sum_{\tau=t}^{\infty} \beta^{\tau-t} \gamma_{\tau+1} \sum_{j=\tau+1}^{\infty} \beta^{j-\tau} d_{j}=\sum_{\tau=t}^{\infty} \beta^{\tau-t} \tilde{\mu}_{\tau} d_{\tau}
$$

where $\tilde{\mu}_{t}=0$ and $\tilde{\mu}_{\tau+1}=\tilde{\mu}_{\tau}+\gamma_{\tau+1}$ for all $\tau \geq t$. This can be derived by expanding the double sum in the left-hand-side and rearranging terms.

Using (29) to eliminate the last term in (28) we get:

$$
\begin{array}{r}
\mathcal{L}=E_{t} \sum_{\tau=t}^{\infty} \beta^{\tau-t}\left\{\lambda_{t} \pi\left(z ; k_{\tau}, l_{\tau+1}, w_{\tau+1}\right)-\left(\lambda_{t}-1-\tilde{\mu}_{\tau}\right) d_{\tau}-\right. \\
\left.\left(\tilde{\mu}_{\tau+1}-\tilde{\mu}_{\tau}\right) \beta D\left(z ; k_{\tau}, \mathbf{s}_{\tau+1}\right)\right\}
\end{array}
$$

If we divide the Lagrangian by $\lambda_{t}$ and define the new state $\mu_{\tau}=\left(1+\tilde{\mu}_{\tau}\right) / \lambda_{t}$, we obtain the saddle-point formulation (9).

Q.E.D.

\section{A.2 Proof of proposition 4.1}

We first prove two lemmas that will be used in the general proof. 
Lemma A.1 Assume that the wage $w$ is constant and $z$ takes only one value. Then the mapping $T$ defined in (22) has a unique fixed point $\bar{V}$.

Proof A.1 Given the continuity of T, it is sufficient to show that this mapping is monotone decreasing and takes values in a bounded and non-empty set. Consider $V_{1}<V_{2}$. The solution of the optimal contract when $\bar{V}=V_{2}$ is also feasible (although not optimal) when $\bar{V}=V_{1}$. In fact, constraint (6) will not be violated if we replace $\bar{V}=V_{2}$ with $\bar{V}=V_{1}$. Therefore, the initial value of the contract for the entrepreneur under $\bar{V}=V_{1}$ must be at least as big as the value under $\bar{V}=V_{2}$. Because there is some contingency in which the solution under $\bar{V}=V_{2}$ is binding when $\bar{V}=V_{2}$ but it is not binding if we replace $V_{2}$ with $V_{1}$, then we can find another contract (or allocation) that is feasible under $\bar{V}=V^{1}$ and increases the value of the entrepreneur without changing the value of the intermediary. Therefore, the mapping $T$ is monotone decreasing.

To prove that the mapping takes values in a bounded set we can show that there are finite lower and upper bounds to the value of $T(\bar{V})$. For any value $\bar{V}, T(\bar{V})$ cannot be negative simply because the entrepreneur's payments cannot be negative. At the same time it cannot be greater than the surplus of an unconstrained firm, otherwise the participation constraint for the intermediary will be violated. The set of values for the mapping is not empty since $T(\bar{V})=0$ is always feasible. This is obtained by not financing new projects. Therefore, $T(\bar{V})$ takes value in a bounded and non-empty set.

Q.E.D.

Lemma A.2 Assume that the wage $w$ and the searching value $\bar{V}$ are constant. Then there exists a unique invariant distribution of firms $\mathcal{M}$.

Proof A.2 The distribution of firms takes a simple structure. In this deterministic environment, firms start with some $\mu=\mu_{0}$ and they reach $\mu=1$ in a finite number of periods $T$. Therefore, the distribution is characterized by $T+1$ groups or types of firms. The first group includes the newly created firms. The second group firms created one year earlier and so on until group $T$. The last group $T+1$ includes firms created $T$ or more periods earlier. This last group includes all the firms with $\mu=1$, that is, unconstrained firms.

Q.E.D.

According to Lemma A.1, for a constant $w$ there exists a unique fixed point $\bar{V}$ and the solution to the contractual problem is well defined. Lemma A.2 then establishes that there exists a unique invariant distribution of firms with associated aggregate demand of labor. If we increase $w$ the demand of labor associated with 
the new invariant distribution must decrease. On the other hand, the supply of labor-implicitly defined by $\varphi^{\prime}(l)=w$-is increasing in $w$. This implies that there exists a unique value of $w$ that clears the labor market and defines the unique steady state equilibrium.

Q.E.D.

\section{B Appendix: Numerical procedure}

Steady state: The steps to solve for the steady state equilibrium with $z_{L}=$ $z_{H}=\bar{z}$ are as follows:

1. We guess the wage $w$ (which is constant in the steady state).

2. We guess the value of searching for a new project $\bar{V}$ (which is also constant in the steady state).

3. Given $w$ and $\bar{V}$, we solve the contract on a grid of points for $\mu$ using the first order conditions. Because $\mu$ never decreases, the model is solved backward starting from $\mu=1$. At $\mu=1$ we know the stock of capital, which is determined by the condition $\pi_{k}=0$. Then the whole sequence of capital at the grid points is determined backward using the equation $k+\bar{V}-\kappa=$ $\beta\left(k^{\prime}+\bar{V}-\kappa\right)$, which is the first order condition (15) evaluated at the steady state. Given the sequence of capital, the grid values of $\mu$ are also determined backward using the equation $\pi_{k}=\beta\left(\mu^{\prime}-\mu\right)$. This is the first order condition (17) evaluated at the steady state.

4. In solving the model we also compute the values of the contract for the intermediary (which we denote by $B(\mu)$ ) and the entrepreneur (which we denote by $\left.W_{\mu}(\mu)\right)$ at each grid point. Values outside the grid are obtained through linear interpolation.

5. Using the zero profit condition for the intermediary we find the initial $\mu$ for a new entrant firm and the corresponding value for the entrepreneur. If this value is different from the initial guess $\bar{V}$, restart the procedure from step 2 until convergence.

6. Given the distribution of firms (which can be determined without iteration given that in the steady state $\mu$ always increases until it reaches 1 ), check the clearing condition in the labor market. Update the wage rate and restart the procedure from step 1 until the labor market clears. 
Aggregate shocks: For each value of $z$ we form a grid of points for $\mu$. Because $z$ takes two values we form two grids. The grid points are determined by solving for the steady state equilibrium in which half of the new firms have $z=z_{L}$ and the other half $z=z_{H}$. The details to solve for the steady state are described above.

For each grid point of $\mu$ and for each $z$, we parameterize three factors: (i) the expected change in $\mu, E\left(\mu\left(\mathbf{s}^{\prime}\right)-\mu\right)$; (ii) the expected value of the contract for the intermediary at the beginning of next period, $E B\left(z ; \mathbf{s}^{\prime}, \mu\left(s^{\prime}\right)\right)$; (iii) the expected value for the entrepreneur at the beginning of next period, $E W_{\mu}\left(z ; \mathbf{s}^{\prime}, \mu\left(\mathbf{s}^{\prime}\right)\right)$. Using the factor $E\left(\mu\left(\mathbf{s}^{\prime}\right)-\mu\right)$ we can solve the first order condition (17). The other two factors are used to compute the current value of the contract for the intermediary, $B(z ; \mathbf{s}, \mu)=\pi\left(z ; k, l^{\prime}, w^{\prime}\right)-d+\beta E B\left(z ; \mathbf{s}^{\prime}, \mu\left(s^{\prime}\right)\right)$, and for the entrepreneur, $W_{\mu}(z ; \mathbf{s}, \mu)=d+E W_{\mu}\left(z ; \mathbf{s}^{\prime}, \mu\left(s^{\prime}\right)\right)$.

At each grid point, the three factors are parameterized with linear functions of: (i) the number of new projects with high productivity, $N$; (ii) the mean value of $\mu$ for low productivity firms, $\int_{\mu} \mathcal{M}\left(z_{L}, \mu\right)$; (iii) the mean value of $\mu$ for high productivity firms, $\int_{\mu} \mathcal{M}\left(z_{H}, \mu\right)$. The last two variables are proxies for the distribution of firms. Values of the factors outside the grid points are determined with linear interpolation. The detailed steps to solve for the equilibrium are as follows:

1. Using a random number generator, we draw a sequence of $N_{t}, t=1, \ldots, T$.

2. We guess the coefficients of the parameterized functions.

3. Given the parameterized functions, we solve the model at each $t=1, \ldots, T$. To solve the model we use the first order conditions (15)-(18), the initial condition for the contract (zero-profit condition for the intermediary), and the market clearing condition in the labor market. Notice that in computing the market clearing conditions we use the true distribution of firms. The approximation based on the use of some of its moments is only for the computation of the three parameterized factors at each grid point.

4. Using the data obtained from solving the model at each $t=1, \ldots, T$, we estimate the coefficients of the parameterized functions with regressions as in Krusell and Smith (1998).

5. The estimates of the coefficients of the parameterized factors are used as new guesses and the procedure is restarted from step 3 until convergence.

For robustness we have also extended the set of moments used to parameterize the three factors without relevant changes in our numerical results. 


\section{References}

Albuquerque, R. and H. Hopenhayn (1997). Optimal dynamic lending contracts with imperfect enforceability. Forthcoming in Review of Economic Studies.

Alvarez, F. and U. Jermann (2000). Efficiency, equilibrium, and asset pricing with risk of default. Econometrica 68(4), 775-97.

Atkeson, A. (1991). International lending with moral hazard and risk of reputation. Econometrica 59(4), 1069-89.

Atkeson, A. and P. Kehoe (2001). The transition to a new economy after the second industrial revolution. Minneapolis Fed Working Paper \# 606.

Atkeson, A., A. Khan, and L. Ohanian (1996). Are data on industry evolution and gross job turnover relevant for macroeconomics? CarnegieRochester Conference Series on Public Policy 44(1), 216-50.

Bernanke, B., M. Gertler, and S. Gilchrist (1998). The financial accelerator in a quantitative business cycle framework. NBER Working paper \#6455, March 98.

Bresnahan, T. F. and F. Malerba (2002). The value of competitive innovation and u.s. policy toward the computer industry. In C.-E. Bai and C.-W. Yuen (Eds.), Technology and the New Economy, Chapter 2. Cambrisgde, Massachusetts: MIT Press.

Cagetti, M. and M. DeNardi (2002). Entrepreneurship, frictions and wealth. Unpublished manuscript, University of Minnesota and University of Virginia.

Carlstrom, C. T. and T. S. Fuerst (1997). Agency costs, neth worth, and business fluctuations: A computable general equilibrium analysis. American Economic Review 87(5), 893-910.

Cooley, T. F. and V. Quadrini (2001). Financial markets and firm dynamics. American Economic Review 91 (5), 1286-1310.

Cordoba, J. C. and M. Ripoll (2002). Credit cycles redux. Forthcoming in International Economic Review.

Demirguc-Kunt, A. and R. Levine (2001). Financial Structure and Economic Growth. Cambridge, Massachusetts: MIT Press. 
DenHaan, W. J., G. Ramey, and J. Watson (1998). Liquidity flows and fragility of business enterprises. Forthcoming in Journal of Monetary Economics.

Djankov, S., R. La-Porta, F. L. de Silanes, and A. Shleifer (2003). Courts. Quarterly Journal of Economics 118(2), 453-517.

Evans, D. S. (1987, August). Tests of alternative theories of firm growth. Journal of Political Economy 95(4), 657-74.

Freeman, C. and L. Soete (1997). The Economics of Industrial Innovation. Cambridge, Massachusetts: MIT Press. Third Edition.

Greenwood, J. and B. Jovanovic (1999, May). The information technology revolution and the stock market. American Economic Review 89(2), $116-22$.

Hobijn, B. and B. Jovanovic (2001). The information-technology revolution and the stock market: Evidence. American Economic Review 91(5), $1203-20$.

Kehoe, T. and D. Levine (1993). Debt constrained asset markets. Review of Economic Studies 60(4), 865-88.

Kiyotaki, N. and J. H. Moore (1997). Credit cycles. Journal of Political Economy 105(2), 211-48.

Knack, S. and P. Keefer (1995). Institutional and economic performance: Cross-country test using alternative institutional measures. Economics and Politics 7(3), 207-27.

Kocherlachota, N. R. (2000). Creating business cycles through credit constraints. Federal Reserve Bank of Minneapolis Quarterly Review 24(3), $2-10$.

Krusell, P. and A. A. Smith (1998). Income and wealth heterogeneity in the macroeconomy. Journal of Political Economy 106(5), 867-896.

Marcet, A. and R. Marimon (1992). Communication, commitment and growth. Journal of Economic Theory 58(1), 219-249.

Marcet, A. and R. Marimon (1997). Recursive contracts. Unpublished manuscript, Pompeu Fabra University.

Mokyr, J. (2002). The Gifts of Athena: Historical Origins of the Knowledge Economy. Princeton, New Jersey: Princeton University Press. 
Monge, A. (2001). Financial markets, creation and liquidation of firms and aggregate dynamics. Unpublished manuscript, Northwestern University.

Phelan, C. (1995). Repeated moral hazard and one-sided commitment. Journal of Economic Theory 66(2), 488-506.

Quadrini, V. (1999). Investment and default in renegotiation-proof contracts with moral hazard. Unpublished manuscript, New York University.

Quadrini, V. (2000). Entrepreneurship, saving and social mobility. Review of Economic Dynamics 3(1), 1-40.

Quintin, E. (2000). Limited enforcement and the organization of production. Unpublished manuscript, Federal Reserve Bank of Dallas.

Smith, A. A. and C. Wang (1999). Dynamic credit relationships in general equilibrium. Unpublished manuscript, Cornegie-Mellon University. 